University of Wollongong

Research Online

Faculty of Social Sciences - Papers (Archive) Faculty of Arts, Social Sciences \& Humanities

2016

HPE teachers' negotiation of environmental health spaces: discursive positions, embodiment and materialism

Nicole Taylor

University of Wollongong, nst25@uowmail.edu.au

Jan Wright

University of Wollongong, jwright@uow.edu.au

Gabrielle H. O'Flynn

University of Wollongong, gabriell@uow.edu.au

Follow this and additional works at: https://ro.uow.edu.au/sspapers

Part of the Education Commons, and the Social and Behavioral Sciences Commons

Research Online is the open access institutional repository for the University of Wollongong. For further information contact the UOW Library: research-pubs@uow.edu.au 


\title{
HPE teachers' negotiation of environmental health spaces: discursive positions, embodiment and materialism
}

\begin{abstract}
A National Curriculum in Health and Physical Education (HPE) has recently been developed in Australia. This new curriculum reflects, among other educational priorities, both environmental sensitivities and a commitment to the enhancement of young people's health and wellbeing. HPE is one of the key sites in the curriculum where a focused consideration of the relationship between the environment and health is possible. However, to date no research has considered the ways that HPE teachers might recognise and negotiate these spaces. The research described in this paper addresses this gap through an analysis of semi-structured interviews with generalist primary and specialist secondary HPE teachers, drawing on a 'narrative ethnography' approach derived from cultural geography. This analysis highlights the consequences of the absence of a knowledge tradition that explicitly links the fields of the environment and health in HPE. Participants who were able to conceptualise environmental health almost exclusively drew on dominant neoliberal and risk discourses. At the same time, teachers' embodied histories and affective encounters with non-human nature helped them to rupture or challenge dominant assumptions about environmental health. We argue that corporeal knowledge developed through embodied experiences has the potential to assist teachers in formulating environmental health in ways that highlight how interactions with the environment might enhance health and wellbeing.
\end{abstract}

\section{Keywords}

teachers, negotiation, environmental, health, positions, spaces, hpe, discursive, materialism, embodiment

\section{Disciplines}

Education | Social and Behavioral Sciences

\section{Publication Details}

Taylor, N., Wright, J. \& O'Flynn, G. (2016). HPE teachers' negotiation of environmental health spaces: discursive positions, embodiment and materialism. The Australian Educational Researcher, 43 (3), 361-376. 


\title{
HPE TEACHERS' NEGOTIATION OF ENVIRONMENTAL HEALTH SPACES: DISCURSIVE POSITIONS, EMBODIMENT \& MATERIALISM
}

\begin{abstract}
A National Curriculum in Health and Physical Education (HPE) has recently been developed in Australia. This new curriculum reflects, among other educational priorities, both environmental sensitivities and a commitment to the enhancement of young people's health and wellbeing. HPE is one of the key sites in the curriculum where a focused consideration of the relationship between the environment and health is possible. However, to date no research has considered the ways that HPE teachers' might recognise and negotiate these spaces. The research described in this paper addresses this gap through an analysis of semi structured interviews with generalist primary and specialist secondary HPE teachers', drawing on a 'narrative ethnography' approach derived from cultural geography. This analysis highlights the consequences of the absence of a knowledge tradition that explicitly links the fields of the environment and health in HPE. Participants who were able to conceptualise environmental health almost exclusively drew on dominant neoliberal and risk discourses. At the same time teachers' embodied histories and affective encounters with non-human nature helped them to rupture or challenge dominant assumptions about environmental health. We argue that corporeal knowledge developed through embodied experiences has the potential to assist teachers in formulating environmental health in ways that highlight how interactions with the environment might enhance health and well-being.
\end{abstract}

Keywords: Health and Physical Education, Socio-material, Embodiment, Environmental Health 


\section{Introduction}

A National Curriculum in Health and Physical Education (AC-HPE) has recently been developed in Australia. This new curriculum reflects, among other educational priorities, both environmental sensitivities and a commitment to the enhancement of young people's health and wellbeing (Australian Curriculum Assessment \& Reporting Authority, 2015a). Within AC-HPE curriculum documents, 'sustainability' is now strongly featured as one of the three cross-curricular priority areas which each curriculum area has to address. Sustainability in the AC-HPE curriculum is addressed by references to students' exploring how they 'develop a connection in and with environments to gain an appreciation of the interdependence of the health of people and that of environments' (ACARA, 2015a). More specifically, HPE students are expected to explore how they connect with natural environments and to consider how these interactions play an important role in 'promoting, supporting and sustaining the wellbeing of individuals, the community and the environment as a whole' (ACARA, 2015a). Further opportunities for thinking about the relationship between the environment and health are identifiable in the response of the AC: HPE to the Aboriginal and Torres Strait Islander cross curriculum priority, where it is proposed HPE can provide the opportunity to explore 'how a sense of connection to Country/Place sustains the health and wellbeing of Aboriginal and Torres Strait Islander Peoples and communities’ (ACARA, 2015a).

These ways of constituting connections between the environment and health are supported by research indicating that contact with natural environments: promotes human physical, psychological, emotional and spiritual wellbeing (Townsend, Maller, St Leger, \& Brown, 2003); aids in enhancing community social capital (Maller, Townsend, Pryor, Brown, \& St Leger, 2006); and fosters an 'ethic of care' whereby individuals feel a responsibility to care for, or protect, 'the environment' (Gray \& Birrell, 2015). Green and Minchin (2014) argue that current health agendas overlook the 'missing dimension of Indigenous connection to Country', and Kingsley, Townsend, Henderson-Wilson, and Bolam (2013) suggest that developing more holistic and less rigid notions of health and wellbeing are necessary to address both inequalities in Aboriginal peoples' health, but also the capacity of humanity 
to deal with environmental issues.

The ways of conceptualising 'environmental health' described above attest to the opportunities for viewing interactions with natural environments as contributing to health and wellbeing. This broader understanding encompasses more than traditional environmental health approaches that investigate the 'toxic' impacts of natural environments on human health (Frumkin, 2001), or the destructive impact humans can have on nature (Strife, 2010). Although both of these latter approaches also present opportunities for discussing environmental health within HPE, our argument in this paper is for the recognition of meanings of environmental health that don't narrow or limit the potential of the 'environment' as a space which might contribute to health in positive ways. We are also interested in examining why, as St Leger (2006) found, environmental health was one of the health areas schools were least satisfied with teaching. To do this, we considered how teachers responsible for teaching HPE in primary and secondary schools conceptualise environmental health. We draw on sociomaterial notions of embodiment to examine the discursive and embodied resources generalist primary and specialist HPE secondary teachers in New South Wales (NSW) schools draw on to talk about environmental health.

\section{Discourses of Environmental Health}

A search for the term 'environmental health' provides multiple hits in the scientific literature documenting the toxic effects the environment can have on human health and wellbeing (Coutts, Forkink, \& Weiner, 2014; Gehle, Crawford, \& Hatcher, 2011; Gregory, 1991). An example of this context is the environmental health work by Hilgenkamp (2006) that details how human activities impact the environment, which then negatively influences the health of all. Drawing on risk discourse and medical/scientific perspectives, Hilgenkamp (2006) outlines the 'effects of various agents on health, assessing risk to human health, and applying ecological principles to minimize or control short term and long term effects on humans' (pg 19). This example draws on risk discourse by chronologically listing and addressing human interaction 'problems' with the environment, such as environmental degradation, species extinction, air pollution and climate change. The author proposes a 
systematic environmental health risk assessment for readers to follow to help them deal with toxic air, water, energy, waste, households and any pollution risk associated with natural disaster (Hilgenkamp, 2006, p. vii). The above example is typical of the type of scientific enquiry that considers the physical environment to be a key determinant of human health.

A neoliberal discourse that dominates the above debate demands that model citizens simultaneously take personal responsibility for both their health and that of the natural environment (Petersen \& Lupton, 2000). Shifting the responsibility for health and the environment onto the individual moralises environmental health related behaviours and lifestyles. This approach to the environment and health has drawn heavily on a discourse of risk. Risk discourse is the platform for many contemporary environmental and health 'truths', including discourses of environmental crisis and 'healthism' (Beck, 2000; Crawford, 1980; Welch \& Wright, 2011). A discourse of environmental crisis, also referred to as the doomsday narrative (Strife, 2010), typically positions the environment as a place of disaster, catastrophe, degradation and sickness. The discourse of environmental crisis also tends to encompass the negative impacts of the environment on human health and wellbeing. Similarly, a dominant 'healthism' discourse positions individuals as being at risk of disease and illness. Within this discourse, individuals are tasked with monitoring and 'working on' their bodies to achieve particular types of health outcomes (Crawford, 1980; Welch \& Wright, 2011). The dominance of these neoliberal and risk discourses in both popular and scientific cultures is significant to determining the conditions of possibility for environmental health knowledge in HPE.

In contrast to a risk based approach to environmental health, there is a much smaller and growing body of literature which encourages those in the medical and scientific professions to move 'beyond toxicity' in imagining the relationship between human health and the natural environment. This literature argues for a move away from teaching about environmental health in ways that centre 'on the hazardous effects of various environmental exposures, such as toxic chemicals, radiation and biological and physical agents' (Frumkin, 2001, p. 234), to recognize that some types of environmental exposures may have positive effects on human health (Coutts et al., 2014). For 
example, Frumkin (2001, p. 234) argues that ‘[a]ccording to E.O. Wilson’s “biophilia” hypothesis, humans are innately attracted to other living organisms' and as such, the focus in medicine should not only acknowledge that environmental exposures can threaten health, but also consider the ways in which contact with nature can enhance health. Drawing on humanistic discourse, this 'positive' approach to environmental health is most often linked to the psychological benefits of spending time in natural environments, such as reduced anxiety and depression, or increases in mental restoration, revitalisation and tranquillity (Johansson, Hartig, \& Staats, 2011).

Within the field of education, researchers are only tentatively creating links between the concepts of the 'environment', 'health', and 'education'. In their review of environmental health research, Sauvé and Godmaire (2004) demonstrate how, as a concept, environmental health education has not been clearly defined nor explored in depth in the academic literature. In the European context Simovska and Mannix-McNamara (2015) draw on the notions of 'Health Promoting Schools' (HPS) and 'Education for Sustainable Development' (EfSD) to make connections between health and the environment. Their linking of the concepts of health and the environment within schooling, however, is based on a Whole School Approach, which is not directly transferrable to the Australian context where health education is one component of the subject area Health and Physical Education (HPE). Gruenewald (2004), on the other hand, utilising a Foucauldian analysis of environmental education in Canada, provides valuable tools to help us think about the place of environmental health in Australian schooling. He argues that environmental education is currently struggling to seek legitimacy within a general schooling system that values literacy and numeracy above all else, thereby silencing the possibilities of 'fringe subjects' such as environmental education. When two highly contested and 'fringe' spaces such as the environment and health come together in the context of education in Australia (where these concepts are widely dispersed throughout curriculum documents), Grunewald's argument that dominant educative discourse is sustaining a hierarchy of subjects, potentially renders environmental health as invisible.

Most recently, critical work by Rodrigues (2014) and Rodrigues and Payne (2015) problematises how 
the environmentalization of physical education curriculum is unfolding in both Australian and Brazilian education systems. While their work makes a significant contribution to linking the concepts of the environment, curriculum and schooling, with overlaps to outdoor education and physical education, they do not make strong links with health education. The absence of a strong tradition explicitly linking the fields of the environment and health in HPE means that educators are potentially left without the language or resources to imagine environmental health education, or to explore the opportunities the concept presents. The space in which attention to the environment has received any focus in relation to HPE is in the context of 'outdoor education'. However, outdoor education in the Australian subject of HPE has itself, over the past 30 years, experienced what Rodrigues and Payne (2015) refer to as an 'identity crisis' and problematic legitimization within curriculum.

While it is important to consider the place of outdoor education in linking the concepts of the environment and health together in HPE, this paper is concerned with the broader conceptualisation of environmental health education, so as not to limit the conversation to teachers who have outdoor education experience only. Consequently the research described in this paper targets all teachers who may have the potential to teach environmental health in the context of HPE, in both secondary and primary school. We consider the discursive and embodied resources they draw on to conceptualise environmental health as a way of providing knowledge that could encourage greater attention to environmental health in the enacted curriculum in schools and teacher education.

\section{Theoretical Framework: Negotiating discursive positions, embodied approaches and the material}

A socio-materialist approach to embodiment provides the means to examine the teachers' discursive and embodied resources drawn on to talk about environmental health. We look particularly to the field of cultural geography where embodied approaches are being employed as a way of theorising cultural environmental relations (Longhurst, 1997), and of understanding 'power, knowledge and social relationships between people and places’ (Longhurst, 1997, p. 486). Cultural geographers, such as Waitt and Frazer (2012), provide an argument for combining embodied approaches with discourse 
analysis. They point to how a focus on embodiment highlights how bodies are sensual and experience cumulative affect (embodied histories) through which individual emotions arise. This understanding is helpful in theorising environmental health negotiations in the context of this study, where cumulative embodied experiences may be significant in shaping participants’ sense of self and identity.

In the field of environmental and outdoor education, scholars are also beginning to attend to embodied, affective responses to natural environments. As a counter to the risk and adventure based tradition of learning in the outdoors, researchers such as Gray and Birrell (2015) suggest that the emotions and learning in the outdoors are closely linked. This recognition of embodied affective experiences in nature leads the authors to examine how complex emotions such as 'love' might be fundamental to negotiations of outdoor and environmental learning. While recognition of the embodied, affective aspects of learning in this field are typically motivated by a desire for behaviour change and development of 'environmental stewards' (Gray \& Birrell, 2015), the approach highlights the potential for unique understandings of environmental health spaces to emerge.

Finally, in response to Williams' (2006) call for new theorizing of bodily interactions, we consider the ways in which the body shapes identity and sense of self, not only through interactions with human social actors, but interactions with the material, or elements of non-human nature. Such discussions of the biological body are rarely present in critical health education literature, however, materialism demands researchers think and act differently when collecting and analysing data (Hultman \& Lenz Taguchi, 2010). The recent work of many ‘new materialists’ such as Barad (2007) demands a move to 're-establish the material in the discursive/material binary’ (Jackson \& Mazzei, 2012, p. 115). Barad (2007) does not necessarily reject the discursive, however conceives of the discursive and material as 'mutually constitutive of one another' and the production of knowledge (Jackson \& Mazzei, 2012, p. 115). Therefore, the actions of a body within its material surroundings are recognised as being acted upon by those surroundings as much as acting on them (Hultman \& Lenz Taguchi, 2010). This requires a theorizing of social relations that not only takes into account 'relations between social actors', but also 'relations between human social actors and elements of non-human nature (Williams, 
2006, p. 17). Plants, water, ecosystems, objects and forces, are all significant to understanding how beliefs are formed around human/nature relationships, and therefore ways of negotiating environmental health spaces. Similarly, Hultman and Lenz Taguchi (2010, p. 525) encourage us to challenge the 'habitual anthropocentric gaze we use when analysing educational data, which takes human beings as the starting point and centre, and gives humans a self-evident higher position above other matter in reality'. The research described in this article takes up this challenge and draws on a socio-materialist approach that values the discursive and material to open up further possibilities for understanding how teachers’ engagement with non-human phenomenon might impact their negotiation of environmental health spaces. It also helps to explain how personal experiences with non-human nature (embodied histories) and affective responses are powerful tools for driving negotiations of environmental health spaces.

\section{Methodology}

This paper draws on data from a larger study designed to explore the potential of environmental health in Health and Physical Education (HPE) as it is taught in Australia. The participants were chosen from known contacts using purposeful and opportunistic sampling in order to reflect a range of perspectives and backgrounds for teachers of HPE (Creswell, 2013). Purposeful sampling is not designed to find a representation indicative of the entire wider population, but rather highlights a search for 'information rich cases' (Baxter \& Eyles, 1997, p. 513). The sampling strategy was particularly useful in this project considering a key aim was to explore the diverse ways environmental health might be negotiated by teachers. The first criterion for participant selection was being an Australian generalist primary teacher or a secondary HPE specialist teacher. We purposefully attempted to select teachers that were at varied stages of the profession, including beginning teachers through to head teachers of HPE and those who were close to the end of their teaching career. Both male and female teachers were invited to participate, along with those who had completed significant portions of their teaching in urban and rural locations. Semi structured interviews were conducted with 12 generalist primary teachers and 12 secondary HPE teachers from NSW. This enabled comparisons to be drawn between two school levels, one where HPE is usually the responsibility of the general classroom teachers and 
the other where it is taught by secondary specialist teachers. The interview questions focused on participants' meanings of environmental health and their encounters with the 'environment' as a health space.

Participant interviews were analysed drawing on the 'narrative ethnography' approach used by Waitt (2010) to identify discursive webs (positions in discourse) and affective aspects (embodied histories) in the teachers' talk about environmental health and their experiences of the environment as a source of wellbeing. Following Waitt (2010), NVivo was used as an analytic tool to assist with the coding of detailed and complex qualitative interview data. Data was coded once for organisation into themed categories using descriptive codes, and a second time, for interpretation of environmental health negotiations using analytical themes that emerged (Waitt, 2010). Participants were offered the protection of anonymity by being allocated fictional names.

\section{Negotiating 'Environmental Health Spaces'}

An analysis of interview data revealed how participants drew on a complex assemblage of meanings and embodied personal histories to talk about environmental health. In particular, three key patterns were identified when participants were asked to define environmental health: firstly a struggle to respond at all to the question; quickly followed by a response which reproduced dominant risk and neoliberal discourses; and finally, more fluent talk about environmental health spaces facilitated by an invitation to talk about their (embodied) personal experiences. However, these patterns were not fixed, nor were they the same for all participants in this study. Often the patterns within generalist primary teacher responses were different to those of secondary HPE teachers. While our analysis helped us to understand the discourses and embodied experiences the HPE teachers' drew on when negotiating environmental health spaces, it is also important to recognise its limitations. What we can’t provide are explanations 'as to why some [discourses], rather than others, are taken up by individuals and why different individuals take up the same discourses in different ways' (Wright, 2003, p. 37). The answer to this question is beyond this paper but is taken up in other discussions arising from the study. 


\section{A Discursive Gap: Struggling to Define Environmental Health}

During the interviews, participants were initially asked to define 'health' broadly and to describe what health meant to them. Although participants had varied responses to this question, all displayed a level of confidence in articulating a conceptualisation of 'health'. Following this discussion, participants were asked to define 'environmental health'. The response to this question that stood out more than any other was one of uncertainty. In eleven of the 24 interviews conducted, the participants struggled to answer the question, using language suggesting a great deal of doubt, for example, silences, long pauses and requests for further clarification of the question. Common responses were: 'Sorry, I don't know', 'I'm not sure' and 'Umm... now that's a hard one'. This struggle to define environmental health was evenly spread across both generalist primary teachers and secondary HPE teachers. The following example is typical of such responses:

I don’t really know... Honestly, as a PDHPE teacher who should be teaching about this stuff in school, I haven't really for 16 years... I don't really know, but I don’t, to be honest, I don’t know much about environmental health. (Kate, 38, Secondary HPE Teacher of 16 years)

According to Foucault (1989), dominant discourses have the power to silence non-dominant ways of thinking and knowing. The initial struggle by many HPE teachers to talk about the 'environment' as a health space highlights how 'environmental health’ can currently be considered a site of subjugated health knowledge in the HPE field. When participants responded in this way, the question was reframed and participants were reassured that they had time to think it through. Once pressed, those who initially struggled to verbalise an answer generally made an attempt to elaborate, typically drawing on dominant risk and neoliberal discourses.

\section{Neoliberal and Risk Discourses}

For those teachers who responded immediately with a definition and for those who responded after some prompting, the most common position was one that drew on dominant risk and neoliberal discourses related to the environment and/or health. These responses drew almost exclusively on 
discourses of environmental crisis, healthism and responsible citizenship. While there were many similarities in the ways the teachers talked about environmental crisis, the generalist primary teachers were more likely to draw on discourses associated with responsible environmental citizenship, compared to the specialist secondary teachers who drew on discourses of healthism.

\section{Environmental Crisis}

Almost half of the participants in our study drew on a discourse of environmental crisis, describing the environment as a place of disaster, catastrophe, degradation and sickness. Both generalist primary and HPE secondary teachers explained their understanding of environmental health, using sensationalised statements such as: the 'declining state of our oceans', 'deforestation increases as a result of human consumption', 'human driven pollution' and 'natural disasters increasing as a result of human driven climate change'. These statements were produced as 'truths' or certainties about the health or state of the environment, with little emphasis on links to human health. Humans were mostly positioned as the reason behind a decline in the health of the natural environment; essentially the environment was at risk from human destruction. In the quote below from Olivia, for example, explains environmental health in terms of the catastrophic state of the environment with references to issues such as bushfire, climate change and deforestation:

\footnotetext{
It's like, you can look around and see - like right now we've got the bushfires and for me it seems clearly obviously that that's related to our doing - humans have done that to the ozone layer - the world is heating up, we know that our weather and climate change is in a bad way... But just down to little things, like the population is growing, we clearly need to teach young people how to live in this world without causing it anymore damage. Because I know that we can’t sustain what we are doing, even in terms of our dietary requirements we can't sustain that in terms of feeding cattle, or feeding any other animal for that sake, because constantly the natural environment is being cut down to make way to put these animals on so that humans can eat them (Olivia, 25, Secondary HPE Teacher of 5 years).
}

In this quote Olivia, like most of the other teachers who spoke in this way about environmental health draws on the language of environmental crisis derived from Western science and the notion that future 
catastrophes can only be avoided if individuals (young people) take more responsibility for their actions. The contradiction here is between the descriptions of disasters arguably caused by government policy and the actions of global agri-businesses and the argument that this can be addressed through personal behaviour change (a common attribute of the neoliberal discourse of individual responsibility). In addition, as scholars have pointed out doomsday narratives, such as that articulated by Olivia, can promote confusion and eco-anxiety, environmental apathy, pessimism about environmental risks (Madden, 1995) and even a phobia of nature (Strife, 2010). If these are the discourses available to teachers to talk about environmental health, they may be inadvertently fostering an aversion to the 'environment' as a health space altogether.

\section{Healthism: The Environment as a Place to Exercise}

While neoliberal discourses of 'healthism' and 'responsible citizenship' were evident in both groups' talk about environmental health, the secondary HPE teachers were more likely to draw on dominant healthism 'truths' (Welch \& Wright, 2011) which described the role of responsible citizens in terms of managing their individual physical activity through the purposeful 'use' of natural environments. For example, nine out of the twelve secondary HPE teachers drew on a healthism discourse to describe environmental health, with comments like: 'the environment is a determinant of individual health', 'physical activity (along with diet) is the most important aspect of health' and 'the natural environment is therefore a great place to be physically active'. What was common among these responses was the idea that the responsible citizen manages their health through exercise, and the natural environment is a space to be utilized to increase physical activity levels. For example:

\footnotetext{
Well I think the environment has a massive role (in health), because it facilitates me being active, that's a big thing. Particularly where we live compared to other places in the world. I haven't lived in other places, but when I think about climates, I mean this is just perfect for being active... So the natural environment and the things we do in it. (Robert, 42, Secondary HPE Teacher of 20 years).
}

For many of the HPE teachers like Robert, who drew on healthism discourses, the natural environment was viewed as an alternative form of 'gym' that could be accessed for exercise. Physical activity 
levels were closely linked to the purpose of working on one's body, which is often cited as the solution for the oncoming of the 'obesity epidemic' (Evans, 2008). However, reproducing a healthism discourse in many contexts has been found to develop problematic norms surrounding bodies, promoting feelings of 'guilt, shame and self surveillance' (Welch \& Wright, 2011, p. 200). Ultimately, while this approach seeks to 'better' human health and wellbeing, it is one which is also individualistic and largely unconcerned with the health status of natural environments. Individuals are encouraged to see natural environments as a resource to promote health through human physical activity. Much of what is driving this healthism discourse is underpinned by Western, medicalised knowledge. What is neglected when we medicalize human relationships with nature, are spaces for social, cultural and spiritual conceptualisations to emerge.

\section{Care for the Environment}

In contrast, the generalist primary teachers tended to draw more on an environmental citizenship discourse (Preston, 2012) in explaining their understanding of environmental health. Most of the primary teachers interviewed referred to the health of the environment in their explanations of environmental health. The language drawn on to explain environmental health was also less prescriptive than the secondary HPE teachers. Rather, they talked about: 'taking care of' and 'looking after' the environment. The narratives in these interviews were about 'humans', in particular 'young people', maintaining a level of care for the environment, taking responsibility and living more sustainably. For example, in the quote below, Genevieve speaks of the health of the environment, in terms of educating young people to care for it:

\footnotetext{
We need to be educating students to care for the environment so they can live in a healthy world when they are older, and also the generations to come. It's a priority because of the direct affects our negative impact has on the future and those who live in the future. Some people only care about themselves, therefore they don't care about the world we've been given to live in and take care of (Genevieve, 24, Primary Teacher of 2 years).
}

'Care' for the environment is a main objective of many modern environmentalists such as Gray and Birrell (2015), who suggest that an emotional attachment to 'nature' is a useful tool to encourage 
action and behaviour change in order to protect it. However, Preston (2012) suggests that an effect of an environmental citizenship discourse is the promotion of a good/bad binary that moralizes environmental behaviour. Citizens can then be scrutinized as 'good' or 'bad' people and stigmatized for not actively 'caring' (Petersen \& Lupton, 2000). This is evident in the way Genevieve judges 'others' as selfish because 'some people only care about themselves'. Shaming, judging and moralising the behaviours of 'others' in this way could shut down the potential for critical environmental health conversations in HPE.

\section{Embodied Affective Histories}

In their initial responses conceptualising 'environmental health' almost all of the participants responded from a ‘teacher’ or professional perspective, even though they were not actually asked to do so. This was perhaps unsurprising, given that participants expected to be interviewed about an educational topic related to their profession. What was surprising, however, was how the majority of conversations transformed once participants were encouraged to think more broadly about environmental health beyond their professional identity. The participants' responses began to draw on more descriptive language, related to embodied experiences that challenged many of the dominant risk and neoliberal discourses they had drawn on earlier in their interviews. Indeed, some participants who initially struggled with their responses and subsequently drew on discourses of environmental crisis, healthism, and responsible citizenship, contradicted these dominant narratives by drawing on encounters with non-human nature that were highly affective. Such ways of speaking about environmental health tended to occur towards the end of the interview, opening up the possibilities for discussion and for multiple understandings of environmental health to emerge. These responses were characterised by narratives that contained affective intensities and embodied encounters, where environmental health was embedded in understandings of the environment as socially and emotionally linked to health, as restorative of wellbeing, and as an imbued connection that was deeply spiritual.

Through embodied encounters with others and non-human nature such as places, animals and gardens, many of the teachers interviewed described affective personal histories that were positive and social. 
For example, Olivia spoke about lived experiences in natural environments that were entangled in social relationships with family and friends, but also non-human nature such as special places and encounters in her backyard:

For me personally it plays quite a large role in my health. I'm - my health is very dependent on my environment, so for example if I am working very hard and I don’t get to connect with nature or go outside or get to the beach or be out in my backyard or my garden, that affects my emotional health straight away. I'll become sad, depressed, and anxious - all those feelings really increase quite quickly, and due to not being able to get outside. As a whole, I get a lot of enjoyment emotionally, spiritually, out of the environment (Olivia, 25, Secondary HPE Teacher of 5 years).

Similarly, in the quote below, Lynne speaks about her understanding of gardening as an environmental health practice that draws on a sense of sharing and community. She describes her embodied experience of gardening as a link to health, relating directly to her interaction with the material - her neighbour, herbs, vegetables, flowers, chooks and eggs:

When I think of it (environmental health) it reminds me of - I always walk past this house near me, their garden, I always think it's a sustainable garden because it's growing herbs, and it's growing vegetables, it's flowers, and it's really pretty to look at, but it's got more use than just one or two... I have chooks in my backyard, we have herbs, we grow some vegetables, we swap eggs, we give eggs to the next door neighbour and she gives us other fresh vegetables. We do what we can. I feel very herbal and healthy sometimes when it's like that (Lynne, 48, Secondary HPE Teacher of 25 years).

Through encounters with non-human phenomenon such as water, trees and sunshine some of the participants described personal embodied experiences that were restorative and enmeshed in conceptualisations of wellbeing. In the following example, Kate's response is typical of those who described an engagement with the ocean or 'nature' in order to 'feel okay' and to be 'healed':

I try and immerse myself in an environment that I feel happy in and feel connected to. And for me that's been down near the water, it's being near the beach and the ocean. Just being near it, hearing it, smelling it... And then when I went through my teenage years, I actually 
went through a really rough time mentally, and had a few issues with eating disorders and just disconnected from the world really, like for probably a year... I vividly remember that the beach was the one place I would go, and I'd go by myself and I'll just sit there, and that was my place that I actually just felt okay in, and felt, again just that connection to. (Kate, 38, Secondary HPE Teacher of 16 years).

What is remarkable is that Kate, who here draws on a powerful embodied experience to help her conceptualise environmental health in her personal life, was one of the many participants who initially found themselves struggling to define 'environmental health'. Kate initially stated that as a PDHPE teacher for 16 years she hadn't taught it, nor did she 'know much about environmental health'. However, Kate's embodied history and her description of the affective and sensory capacity of water to make her feel 'okay', 'happy’ and 'connected' tell another story.

Some of the participants spoke of environmental health in terms of experiences in natural environments that were entangled with spiritual health. Many of the encounters described were experienced with a significant person. This significant person was almost exclusively a father (in one instance a male teacher). These embodied experiences weren’t always explicitly linked to religion; however many participants told narratives that indicated a deeply personal understanding of spirituality as a connection to non-human nature. Their embodied histories provided the means for the participants to construct narratives that were explicitly linked to unique understandings of the interplay between environments and health:

It (environmental health) makes me think of my father who passed away a long time ago now. He used to be more a person who found great solace within the environment. So you would see him... and he would be squatting out under a tree. Yeah that's a really strong image of him under a tree. He wasn't religious dad - and when he died we didn’t do it with the church - and they were getting me to tell them about him. So I had to organise it and I was trying to tell them about dad and what he was like. But what I tried to say was - no he wasn’t a religious man, but he’s a spiritual man. And that essence of him sitting out under the tree in the environment - that is a really strong image for me of someone who is quite 
spiritual. I know - it’s hard to explain (Shelly, 56, Primary Teacher of 28 years).

While neoliberal and risk discourses described earlier in this paper are constituted in and through scientific and Western knowledge systems as 'truth', spiritual understandings tend to privilege the 'emotion and feeling over reasoning, the rural over the urban, the natural over the artificial' (Petersen \& Lupton, 2000, p. 104). Shelly's above response was typical of several teachers who drew on embodied histories with fathers and the affective capacity of 'nature', 'tree' and 'environment' to feel 'respect', 'admiration' and a 'spiritual connection'. These embodied experiences resonate with what modern HPE texts refer to as the spiritual dimension of health, defined as 'a positive sense of belonging, meaning and purpose in life, includes values and beliefs that influence the way people live, and can be influenced by an individual's connection to themselves, others, nature and beyond' (Australian Curriculum Assessment \& Reporting Authority, 2015b). Unfortunately, approaches that place an emphasis on spiritual connections to nature are widely criticized for being romanticized and utopian (Petersen \& Lupton, 2000) and are typically at odds with the ways Western science determines 'truth'. This means that such ways of conceptualizing environmental health are likely to remain forms of subjugated knowledge unless a critical mass of argument is mobilized to support them.

\section{Conclusion}

When initially engaging in discussion around environmental health, both primary and HPE secondary teachers in our study struggled to talk about the environmental health space. However, given the current opportunities for teaching about environmental health concepts, this position of struggle identifies a need to begin conversations about the term 'environmental health' in HPE. Unfortunately, resources for thinking about environmental health education in Australia are severely limited. The initial response by many participants suggests that it is difficult for HPE educators to link the 'environment' and 'health' without the resources or language to help them think about the possibilities in this space. For teachers in this study to experience an initial position of struggle was not surprising to the authors of this paper, considering the lack of a strong tradition in HPE linking concepts of the environment and health together. 
It is also not surprising that the second default position for many of the teachers was to draw on dominant risk and neoliberal discourses, reproducing the 'certainties' of environmental crisis, healthism and responsible citizenship. However, as some critical health and environmental researchers have pointed out, these dominant narratives can be considered problematic for the ways they can develop confusion and environmental apathy (Strife, 2010), along with health practices that promote feelings of shame, guilt and self surveillance (Welch \& Wright, 2011). Our concern is that the lack of a strong knowledge tradition explicitly linking the environment and health together in HPE could result in the reproduction of dominant discourses that are possibly harmful, limiting the potential of environmental health education. Our results suggest that if teachers are encouraged to move beyond the reproduction of dominant risk and neoliberal discourses, then corporeal knowledge developed through personal embodied histories holds value for the contribution it brings to complex environmental health understandings. Embodied, affective histories and social interactions, including those with the material and non-human phenomenon, highlight the potential for environmental health negotiations. We suggest that this points to the need to value multiple ways of knowing the environmental health space.

Finally, our results also highlighted that there is currently a barrier preventing primary and HPE secondary teachers from transferring complex environmental health understandings from embodied personal experiences to professional contexts. While the answer to this question falls beyond the purpose of this paper, it is an area that needs further research and understanding, as it holds implications for considering how teachers deliver environmental health education in schools. It is also an area in which we suggest there may be a need for professional learning experiences as the Australian Curriculum is implemented nationwide. We would like to think that it is possible to move beyond dominant narratives of the environment and health that may limit teacher, and subsequently student, understandings of environmental health as a valuable space for exploration in HPE.

Note: Formal ethical consent to conduct this project was gained from the affiliated University. 


\section{References}

Australian Curriculum Assessment \& Reporting Authority. (2015a). Health and Physical Education. The Australian Curriculum v7.3. Retrieved 26/1/2015, from http://www.australiancurriculum.edu.au/health-and-physical-education/crosscurriculum-priorities

Australian Curriculum Assessment \& Reporting Authority. (2015b). Health and Physical Education: Glossary. The Australian Curriculum v7.3. Retrieved 26/1/2015, from http://www.australiancurriculum.edu.au/health-and-physical-education/glossary

Barad, K. (2007). Meeting the Universe Halfway [electronic resource]: Quantum Physics and the Entanglement of Matter and Meaning. Durham: Duke University Press.

Baxter, J., \& Eyles, J. (1997). Evaluating qualitative research in social geography: establishing 'rigour' in interview analysis. Transactions of the Institute of British Geographers, 22(4), 505-525.

Beck, U. (2000). Risk Society Revisited: Theory, Politics and Research Programmes. In B. Adam, U. Beck, \& J. v. Loon (Eds.), The risk society and beyond: critical issues for social theory. London: SAGE.

Coutts, C., Forkink, A., \& Weiner, J. (2014). The portrayal of natural environment in the evolution of the ecological public health paradigm. International Journal of Environmental Research and Public Health, 11(1), 1005-1019.

Crawford, R. (1980). Healthism and the medicalization of everyday life. International Journal of Health Services, 10(3), 365-388.

Creswell, J. W. (2013). Qualitative inquiry and research design: choosing among five approaches: Thousand Oaks: SAGE Publications.

Evans, J. (2008). Education, disordered eating and obesity discourse: fat fabrications. New York: Routledge.

Foucault, M. (1989). The archaeology of knowledge. New York: Routledge.

Frumkin, H. (2001). Beyond toxicity: human health and the natural environment. American Journal of Preventive Medicine, 20(3), 234.

Gehle, K. S., Crawford, J. L., \& Hatcher, M. T. (2011). Integrating environmental health into medical education. American Journal of Preventive Medicine, 41(4, Supplement 3), S296S301.

Gray, T., \& Birrell, C. (2015). Touched by the Earth: a place-based outdoor learning programme incorporating the Arts. Journal of Adventure Education and Outdoor Learning.

Green, D., \& Minchin, L. (2014). Living on climate-changed Country: Indigenous health, wellbeing and climate change in remote Australian communities. EcoHealth, 11(2), 263-272.

Gregory, R. (1991). Critical thinking for environmental health risk education. Health education quarterly, 18(3), 273-284.

Gruenewald, D. A. (2004). A foucauldian analysis of environmental education: Toward the socioecological challenge of the Earth Charter. Curriculum Inquiry, 34(1), 71-107.

Hilgenkamp, K. (2006). Environmental Health: Ecological Perspectives. Sudbury, Mass: Jones and Bartlett Publishers.

Hultman, K., \& Lenz Taguchi, H. (2010). Challenging anthropocentric analysis of visual data: a relational materialist methodological approach to educational research. International Journal of Qualitative Studies in Education, 23(5), 525-542.

Jackson, A. Y., \& Mazzei, L. A. (2012). Thinking with theory in qualitative research: viewing data across multiple perspectives. New York Routledge.

Johansson, M., Hartig, T., \& Staats, H. (2011). Psychological benefits of walking: Moderation by company and outdoor environment. Applied Psychology: Health and Well-Being, 3(3), 261-280.

Kingsley, J., Townsend, M., Henderson-Wilson, C., \& Bolam, B. (2013). Developing an exploratory framework linking Australian Aboriginal peoples' connection to Country and concepts of wellbeing International Journal of Environmental Research and Public Health, 10, 678-698. 
Longhurst, R. (1997). (Dis)embodied geographies. Progress in Human Geography, 21(4), 486-501. Madden, K. (1995). Householders' experiences of 'save the environment' messages. Australian Journal of Communication, 22(3), 82-102.

Maller, C., Townsend, M., Pryor, A., Brown, P., \& St Leger, L. (2006). Healthy nature healthy people: 'contact with nature' as an upstream health promotion intervention for populations. Health Promotion International, 21(1), 45-54.

Petersen, A., \& Lupton, D. (2000). The New Public Health: Health and Self in the Age of Risk. London: SAGE Publications Ltd.

Preston, L. (2012). Changing green subjectivities in outdoor and environmental education: A qualitative study. Discourse, 33(2), 235-249.

Rodrigues, C. (2014). The environmentalization of physical education in higher education settings: environmental dimensions of academic units in federal universities of Brazil. Paper presented at the 6th International Conference on Environmental Education and Sustainability: The Best of Both Worlds, Sao Paulo, Brazil. http://www.bestbothworlds2014.sc.usp.br/wpcontent/uploads/2014/11/00_AF_INGLE\%CC\%82S_DIGITAL_3.0_FINAL.pdf

Rodrigues, C., \& Payne, P. (2015). Environmentalization of the physical education curriculum in Brazilian universities: culturally comparative lessons from critical outdoor education in Australia. Journal of Adventure Education and Outdoor Learning. doi:10.1080/14729679.2015.1035294

Sauvé, L., \& Godmaire, H. (2004). Environmental health education: A participatory holistic approach. EcoHealth, 1(2), SU35-SU46.

Simovska, V., \& Mannix-McNamara, P. (2015). Schools for Health \& Sustainability: Theory, Research and Practice. Netherlands: Springer.

St Leger, L. (2006). Health Promotion and Health Education in Schools: Trends, Effectiveness and Possibilities: Research Report. Noble Park North, Victoria: RACV.

Strife, S. (2010). Reflecting on environmental education: Where is our place in the green movement? Journal of Environmental Education, 41(3), 179-191.

Townsend, M. A., Maller, C., St Leger, L., \& Brown, P. (2003). Using environmental interventions to create sustainable solutions to problems of health and wellbeing. Environmental Health, 3(1), 58.

Waitt, G. (2010). Doing foucauldian discourse analysis: Revealing social realities. In Hay (Ed.), Qualitative Research Methods in Human Geography (3rd ed.). Oxford: Oxford Press.

Waitt, G., \& Frazer, R. (2012). "The vibe" and "the glide": surfing through the voices of longboarders. Journal of Australian Studies, 36(3), 327-343.

Welch, R., \& Wright, J. (2011). Tracing discourses of health and the body: exploring pre-service primary teachers' constructions of 'healthy' bodies. Asia Pacific Journal of Teacher Education, 39(3), 199-210.

Williams, S. (2006). Medical sociology and the biological body: where are we now and where do we go from here? Health: An Interdisciplinary Journal for the Social Study of Health, Illness and Medicine, 10(1), 5-30.

Wright, J. (2003). Poststructural methodologies - The body, schooling and health. In J. Evans, B. Davies, \& J. Wright (Eds.), Body Knowledge and Control. Studies in the Sociology of Physical Education and Health (pp. 34-59): Routledge. 